\title{
MAPPING FOREST AND AGROFORESTRY UNITS FOR ENVIRONMENTAL PLANNING. STUDY CASE TRANSBOUNDARY REGION MEXICO-GUATEMALA
}

\author{
Daniel López L ${ }^{1 *}$, Aristides Saavedra G. ${ }^{1}$ \\ Tlalpan, C. P. 14240, México D. F. \\ *Corresponding author: dlopez@centrogeo.edu.mx

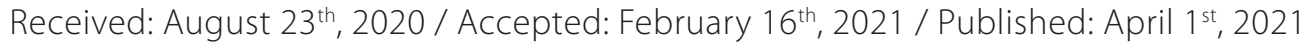 \\ https://DOl-10.24057/2071-9388-2020-193
}

${ }^{1}$ Centro de Investigación en Ciencias de Información Geoespacial, Contoy 137, Col. Lomas de Padierna, Delegación

\begin{abstract}
The cross-border region of Mexico and Guatemala is part of the continuum in the aspects of relief, climate, hydrography, geology, land cover and land use of Mesoamerica, one of the most biologically diverse regions on the planet. Historically, the region has been continuously affected by meteorological phenomena, such as mass movement in the highland and floods in the lowland, which affected cities, communities and production activities year after year and led to the loss and deterioration of the ecosystems. To handle this problem, a proposal for environmental planning is suggested. The final objective is to provide key information that concerns the implementation of Sustainable Development Goals, particularly related to the protection and restoration of forest areas. In this study, spatial analysis and modeling were applied to map homogeneous units for environmental planning in the Mexico-Guatemala trans-border region. Additionally, forest area as a proportion of the total land area, its share inside the natural protected areas and distribution by ecosystem type were calculated for 2010 and 2019. From the data analysis it was found that the total forest area in the region has decreased from 47\% in 2010 to $43 \%$ in 2019; 27\% and 25\% of the total area, respectively, correspond to forests within the natural protected areas. The principal ecosystem type in the Natural Protected Areas corresponds to tropical forest. Two conclusions can be drawn, that agroforestry zoning is an important tool to monitor forest areas in the context of achieving Sustainable Development Goals and that the natural protected areas play a fundamental role in the preservation of the forest in the region.
\end{abstract}

KEY WORDS: Mapping, forest, agroforestry, natural protected area

CITATION: Daniel López L., Aristides Saavedra G. (2021). Mapping Forest And Agroforestry Units For Environmental Planning. Study Case Transboundary Region Mexico-Guatemala. Geography, Environment, Sustainability, Vol.14, No 1, p. 63-70 https://DOl-10.24057/2071-9388-2020-193

Conflict of interests: The authors reported no potential conflict of interest.

\section{INTRODUCTION}

The cross-border region' of Mexico and Guatemala is a part of the continuum in the aspects of relief, climate, hydrography, geology, land cover and land use of Mesoamerica, one of the most biologically diverse regions on the planet. It is one of the most important areas among the world's 25 biodiversity "hotspots" in terms of species diversity and endemism (Conservation International - México and Central América Program, 2004).

In this region, natural vegetation with a little degree of intervention (forests and wetlands), which is found mainly in natural protected areas, comprises $42.7 \%$ of the total area. The other $54.7 \%$ of the area corresponds to the coverage associated with anthropogenic action that includes grassland, agriculture, plantations, shrub vegetation and urban areas (Lopez D. y Saavedra A., 2019). Many of the agricultural areas are located on hillside lands with slopes of $12-50 \%$ and higher and shallow soils, which are not suitable for such purposes. For this reason, the agricultural activity causes the processes of land degradation (water erosion, deforestation, loss of biodiversity) in highland, which translates into floods in the lower areas due to the high runoff generated in the upper parts of the watershed. In the last two decades, the cross-border region has become a territory of major social changes due to the impact of the different socioeconomic, political and environmental processes.

Historically, the region has been continuously affected by meteorological phenomena, such as mass movement in the highland and floods in the lowland, which affected cities, communities, production activities and natural resources year after year. This vulnerability increases with global warming and increasing human intervention (fires, deforestation and drying of wetlands) as well as from inadequate land use and management leading to the loss and deterioration of the ecosystems, which modifies the hydrological dynamics of watersheds.

In response to this problem, a proposal for environmental planning and management with an emphasis on forest and agroforestry systems is suggested. Based on this, appropriate public, federal, local and binational policies that allow the cross-border region to ensure the quality of life, environmental sustainability and shared development can be adopted.

${ }^{1}$ The area considered here is the one defined by the authors in the Project: "The natural environment and land suitability as a base for rural management, Cross-border Mexico-Guatemala". 
The final objective is to provide the information for decision-making that ensures the conservation, restoration and sustainable use of terrestrial and inland freshwater ecosystems, including forests, wetlands and mountains, in line with the obligations under international agreements, as stated by the Sustainable Development Goals, particularly the Goal 15: Protect, restore, and promote sustainable use of terrestrial ecosystems, sustainably manage forests, combat desertification, and halt and reverse land degradation and halt biodiversity loss. Additionally, as part of the data analysis, the following indicators proposed for this goal will be reflected: the proportion of forest area in the total land area and proportion of important sites for terrestrial and freshwater biodiversity that are covered by protected areas, by ecosystem type. Finally, an analysis of the evolution of these indicators for the considered area between the years 2010 and 2019 will be conducted. Zoning and management of forest areas is a key element to encourage their protection and restoration as well as promote sustainable use of terrestrial ecosystems

Zoning as an instrument of planning facilitates the identification of geographical areas with a combination of physical, biological, human and institutional features that can be interpreted in terms of objectives for the management. The application of this instrument must be supported by information that enables the analysis of different environmental processes describing the heterogeneity of the study area (Ortiz-Lozano et al. 2009).

The zoning of the aptitude of territory represents its division into homogeneous zones based on environmental criteria, which is considered a synthesis of the biophysical, socio-cultural and economic conditions, and at the same time, a basis for a proposal for environmental management. This analysis allows to produce differentiated recommendations of the interventions and actions that have to be taken. The zoning seeks to ensure an adequate supply of environmental goods and services that responds to the objectives of management through the optimization of the uses of territory in specific units (Valenzuela and Silva 2003).
The territorial zoning, which is usually seen as a methodological tool that allows the spatial differentiation of geographical areas, has been applied for planning and arranging of the territory (López et al. 2012; López D. and Saavedra A. 2007, 2019; López D., Saavedra A. and Castellanos L. 2016; Domínguez et al. 2008). The use of this approach as a basis for land-use regulation enriches the knowledge of natural resources distribution, its dynamics in time and tolerance of the environment to human intervention. Also, it allows to evaluate the productive aptitude of the territory and the potential conflicts between the aptitude and the current use of soil. In this sense, the spatial arrangement in "homogeneous" units in this project will constitute the physical natural sustenance for the design and application of policies and programs of land management.

\section{MATERIAL AND METHODS}

\section{The study area}

The study area (Figure 1) covers an approximate surface of $116,008.6 \mathrm{Km}^{2}$ and consists of five physiographic regions: the Yucatán platform in the north, the Sierra Madre of Chiapas and Guatemala, the Central American Cordillera and the Central Depression of Chiapas in the central part, and the Pacific Plain towards the southwest (Saavedra A. and Castellanos L. 2013).

The study area includes parts of the Mexican states of Chiapas, Campeche and Tabasco. The first two occupy most of the area as Chiapas represents about half of the delimited area. On the Guatemala side, there are the departments of Petén (the largest in the study area), Alta Verapaz, Quiché, Huehuetenango, San Marcos, Quetzaltenango and Retalhuleu. According to the data from the EMIF survey (www.colef.mx/emif), at the end of 2016, a number of people crossed the Mexican border from the south for work reasons, of which more than 700,000 were from Guatemala. This indicates the enormous scale of the current regional exchange processes (Tonatiuh 2017a).

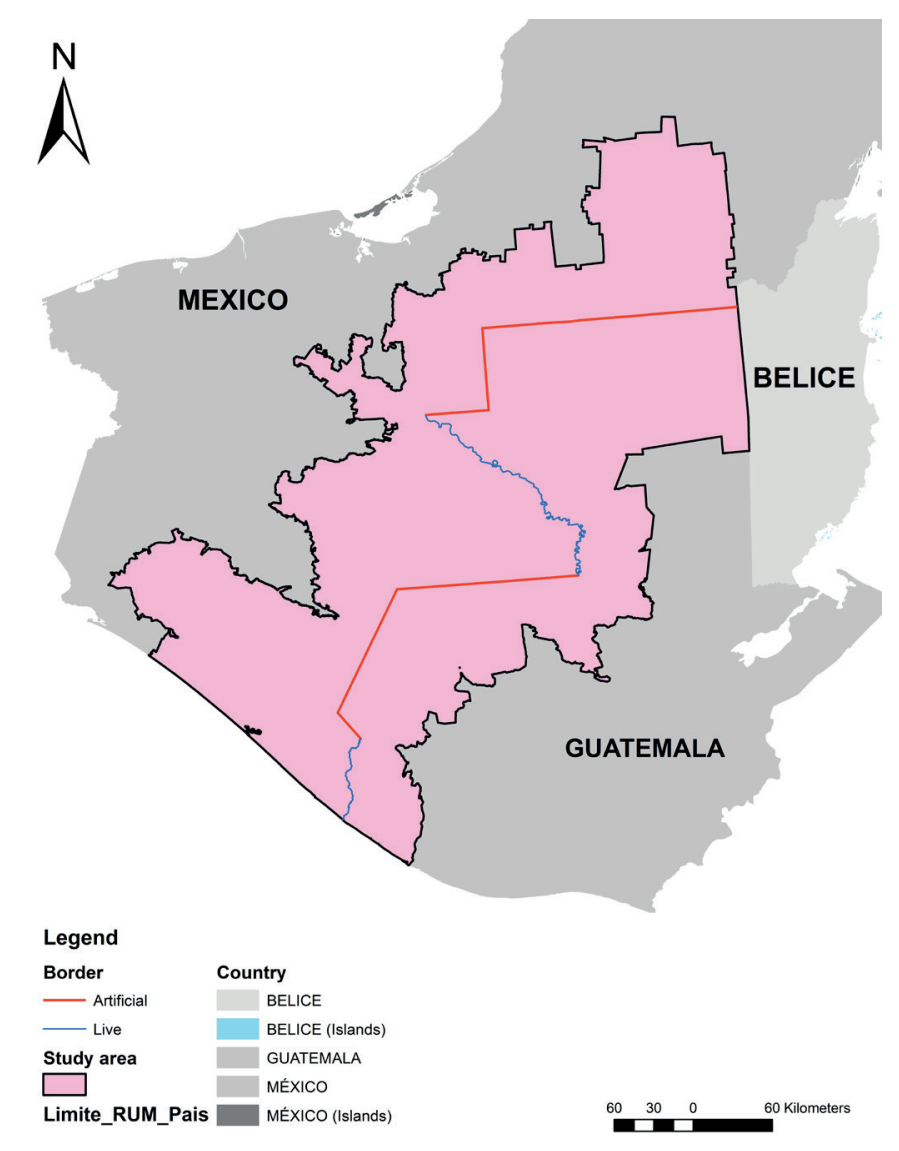

Fig. 1. The area of the cross-border region of Mexico and Guatemala 
In terms of the localities distribution, there is a large concentration of these in the southwestern sector of the border, which translates into a very marked distribution of population density as it shows its highest values in a low number of municipalities on both sides of the border.

Various Natural Protected Areas (NPAs) have been decreed to preserve and protect the natural heritage in the cross-border region, their location is shown in Figure 2. In Mexico, the NPAs that stand out for their size are the Biosphere Reserves (La Sepultura, El Triunfo, La Encrucijada) on the Pacific side and "Montes Azules" and "Calakmul" on the Gulf of Mexico and Caribbean sides. In Guatemala, the study region covers most of the Maya Biosphere Reserve (RBM) as well as the "Sierra de Lacandon" National Parks and "Laguna del Tigre". The NPAs on both sides of the border include various ecosystems that gather great biological and cultural diversity, which corresponds particularly to tropical rain forests that persist as a continuum, especially in the northeast and center of the study area, and to a lesser extent in the southwest sector. On the contrary, the natural ecosystems outside the protected natural areas are mostly transformed by the different production activities that have caused great changes in land use.

Most of the study area corresponds to lowlands with altitudes less than 500 meters above sea level, the slope in these areas is below 7\%. The rest of the area, approximately a third, is located within 1000 and 4000 meters above sea level and has predominant slopes of $12-25 \%$ and $25-50 \%$ as well as small sectors with slopes of $50-75 \%$ and greater than $75 \%$.

\section{Methodology}

In this study, spatial analysis and modeling were used to identify and map homogeneous units for environmental planning and management in the Mexico-Guatemala trans-border region, the used methodological approach is presented in Figure 3. The data used in this study include: Digital elevation model. Elevation data were obtained with a spatial resolution of 30 meters (ASTER GDEM version 3); from this DEM the slope was calculated.

Soils map (INEGI, SERIE II, 2008) and for Guatemala the database of Winograd M. and Farrow A. (2000)

Land cover and land use map (INEGI Series $V$ and Series VI; CONANP, MAGA - PGGR, Guatemala, 2010 and updated with Sentinel images, 2019)

Land suitability map (Lopez D. and Saavedra A. 2019)

Natural protected areas map (CONANP, México - IGN, Guatemala)

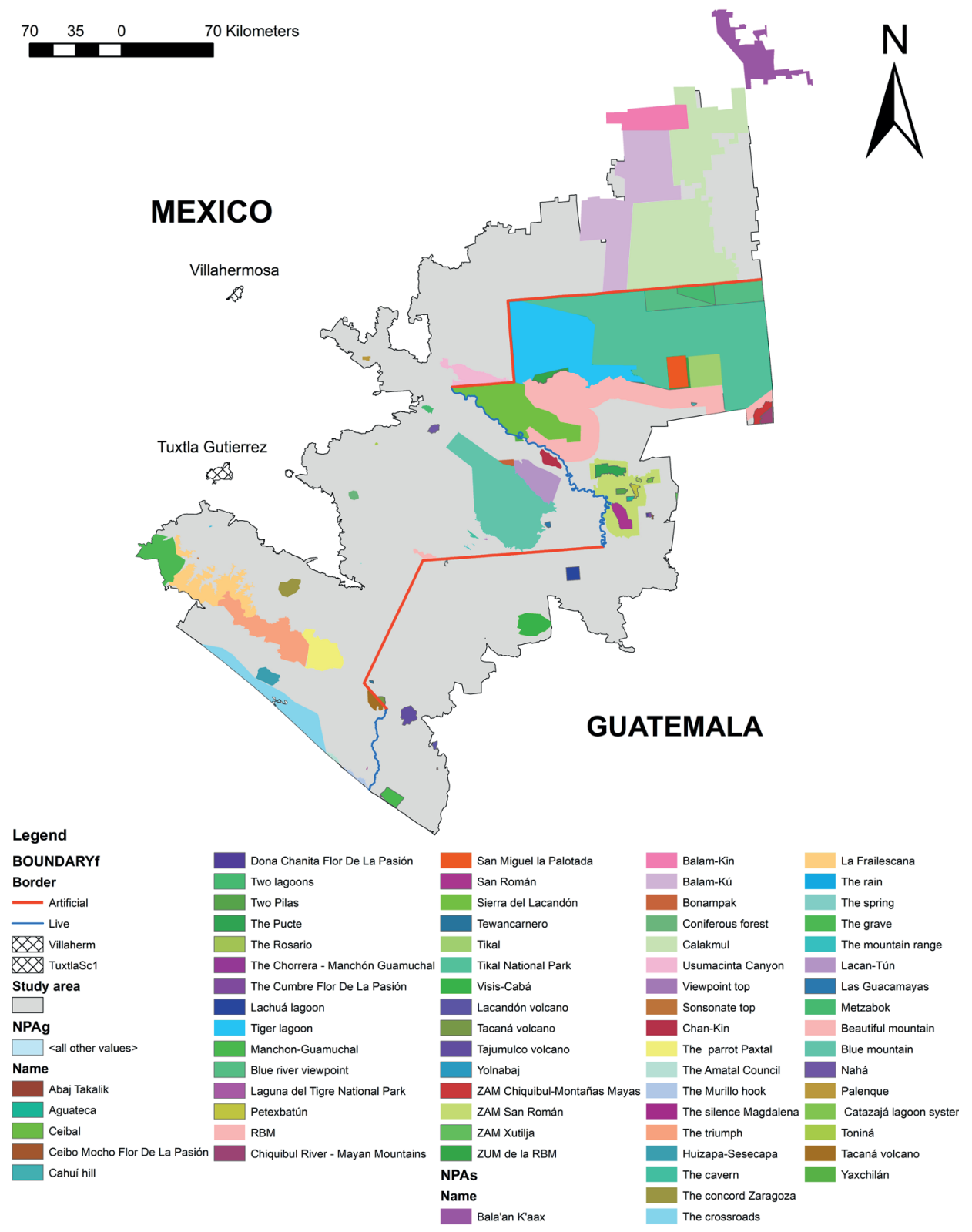

Fig. 2. Natural protected areas in the Mexico-Guatemala cross-border region 


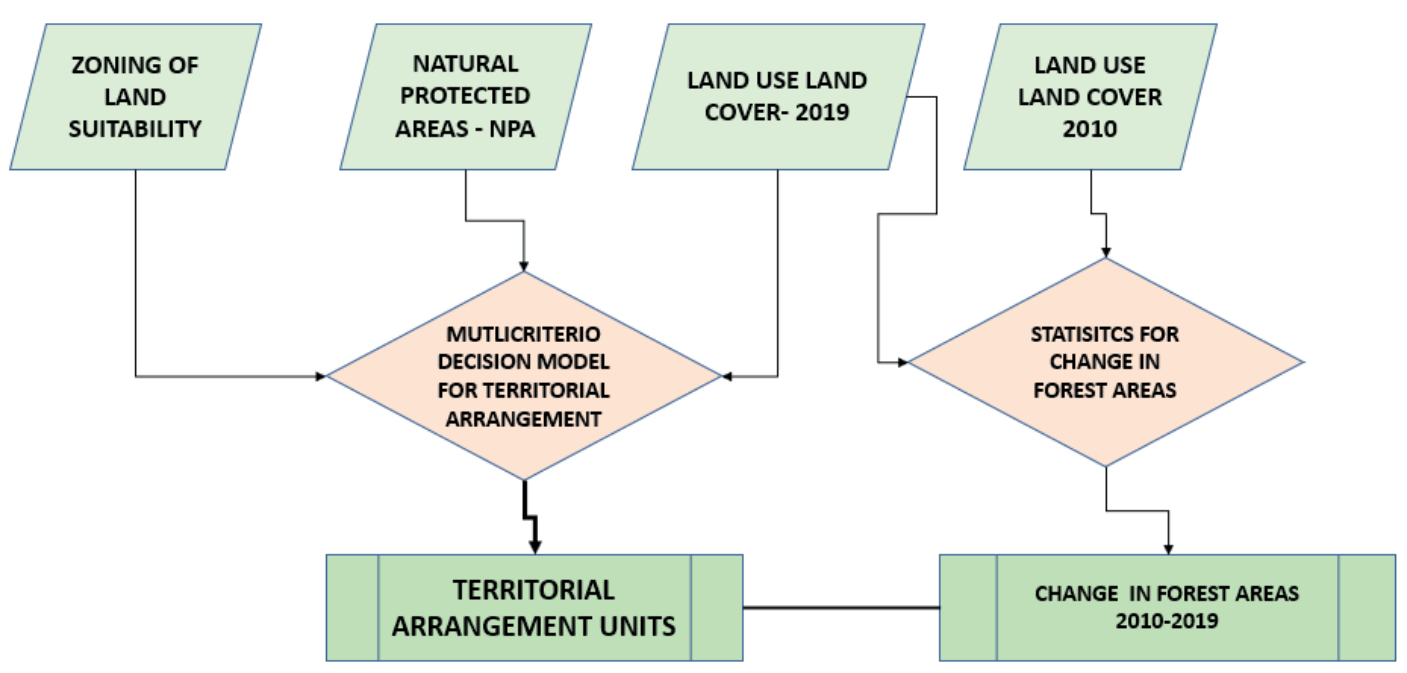

Fig. 3. Methodological approach

The units of land suitability were defined by the Land capability classification system developed by the Soil Conservation Service of the United States-USDA, 1965, adapted by IGAC, 2001, which was modified for the present study based on the available pedological information (listed above); the classification of soils in this map is referring to the FAO classification system (FAO/UNESCO, 1998). The first two dominant soils (Group1 and Group 2 in such database) were considered in the development and choice of the criteria for the limiting factors. Susceptibility to erosion, the slope (\%), natural drainage, susceptibility to flooding, effective depth, soil fertility and salinity/sodium conditions were considered as the limiting factors.

Land suitability is the base for the territorial arrangement, which was modeled together with the current land use and land cover through rules of decision and having the natural protected areas as a frame. The rules of decision were defined using "Criteria for the integration of the territorial arrangement with an emphasis in forest and agroforestry systems" of the Mexican National Forest Commission-CONAFOR (CONAFOR, 2011) as a base, which was adapted and modified for the present study. The implementation of the rules of decision was made through a conditional algorithm using the "Modeler" module of ERDAS Imagine, Version 10.0. The result was the map of the territorial arrangement, which was structured in zones, sub-zones and management units.

Criteria for the integration of the territorial arrangement with an emphasis on forest and agroforestry systems.

In this study, the criteria for the territorial arrangement were based on the "Agreement on the integration and organization of the Forestry Zoning" by CONAFOR, which has been adapted and modified by the authors. According to the Article 4 of the above-mentioned agreement, the structure of the Forest Zoning distinguishes three categories: 1) areas of conservation and restricted or prohibited use; 2) production /use areas; 3) restoration areas. To account for the lowland, which requires regulation of the runoff originated from the highland, the spatial arrangement proposed in this study included a special category "regulatory and buffer area". In the next paragraph, the criteria that define the zones, subzones and management units are described.

I. Conservation and restricted or prohibited use zones. These areas were identified by their specific natural conditions or by their protection status. Two subzones were distinguished: a) Subzone of land in the Natural Protected Areas. These areas are subject to a special regime of protection, conservation and restoration according to categories established in the General Law of the Ecological balance and environmental protection (DOF 05-112013); b) Subzone of land for Conservation - Protection. This subzone includes natural areas that are marked by very steep slopes or are covered by natural vegetation (temperate and tropical forests).

II. Regulatory and buffer zone. This is a type of land, the physiographic position and natural vegetation cover of which play an important role in the environmental regulation and buffering of water flows, including wetlands (bodies of water and hydrophilic vegetation). Only one sub-zone is defined: a) Sub-zone of land for buffering and wetlands protection.

III. Production / use zone. This area has conditions of vegetation and soil suitable for agricultural, livestock and forestry production in a sustainable way, including timber and non-timber production for multiple uses: firewood, construction, live fences, food, fodder, medical and handicraft. Includes four sub-zones: a). Subzone of lowland with high to moderate suitability, which corresponds to land with slight to moderate limitations for agricultural, livestock and forestry (plantations) production; b) subzone of lowland with restricted suitability to some uses. It is suitable for the livestock and forestry plantation, with species improved and adapted to the specific conditions of these environments; c) subzone of hilly land with moderate aptitude; d) subzone of hilly land with low aptitude.

IV. Restoration zones. This corresponds to terrain with forestry aptitude, that is devoted to other uses or is in the process of degradation from inadequate land use and management. These areas comprise two sub-zones: a) Subzone of hilly land with very severe susceptibility to water erosion and b) Subzone of hilly land with shrubby secondary vegetation of the tropical humid and temperate forest, with moderate to severe susceptibility to water erosion.

\section{RESULTS AND DISCUSSION}

\section{Agroforestry zoning}

The results of zoning are presented on the map in Figure 4. From the perspective of sustainable development goals, the information presented in Figure 4 can be summarized as follows: a) conservation areas are proposed 
for all territories with forest cover whether they are inside or outside the natural protected areas, this would allow to at least maintain the proportion of the forest cover in the study area; b) areas for restoration of vegetation cover with different priority levels are proposed. The higher priority is assigned for the areas delimited as restoration/ conservation zones since they are located on very steep slopes, where the presence of natural vegetation is essential to avoid land degradation processes. The second priority is given to the lands located in the natural protected areas, which have been transformed by the impact of anthropogenic activities and currently have shrub vegetation cover. In the third place, there are the areas delimited on the map as restoration - exploitation zones, which are currently dedicated to annual crops, an activity that is not very suitable for steep slopes. In these areas, it proposed to restore the natural vegetation or to dedicate them to more environmentally friendly crops, such as agroforestry(coffee).

Land cover - land use inside and outside the natural protect areas

The results of the spatial analysis of the land cover and land use distribution inside and outside the natural protected areas (NAP) for the years 2010 and 2019 are shown in Figures 5 to 9 and Table 1. In the study area, the following ecosystems can be distinguished: agroecosystem (crops, pasture, plantation), mangrove swamp - wetland, mountain mesophyll, temperate and tropical forest (perennial, sub-deciduous). Table 1 shows the areas for each of the land use and land cover types, Figures 5 and 6 show their spatial distribution. According to the table, in 2010, the forest area comprised a total of $55,078.17 \mathrm{~km}^{2}$, which is equivalent to $47.5 \%$ of the study area, and $27.7 \%$ corresponded to forests in the natural protected areas. In 2019 , forests covered an area of $49,817.78 \mathrm{~km}^{2}$, which is equivalent to $43.2 \%$ of the study area, with $25.2 \%$ being located within the natural protected areas. According to these data, there was a decrease in the total forest area of approximately $4 \%$, while in the natural protected areas it decreased by approximately $2 \%$. However, it is important to mention that the natural protected areas make up approximately $60 \%$ of forests in the study area, in general, this amount remains constant over the considered period. On the other hand, the area of anthropogenic coverage has increased from 43,190.8 $\mathrm{km}^{2}$ in 2010 , which is equivalent to $37.2 \%$ of the total area, to $53,017.7 \mathrm{~km}^{2}$ or $45.2 \%$ of the total area, in 2019. A significant increase has occurred in the area of plantations and oil palm, mainly in the Guatemala sector.

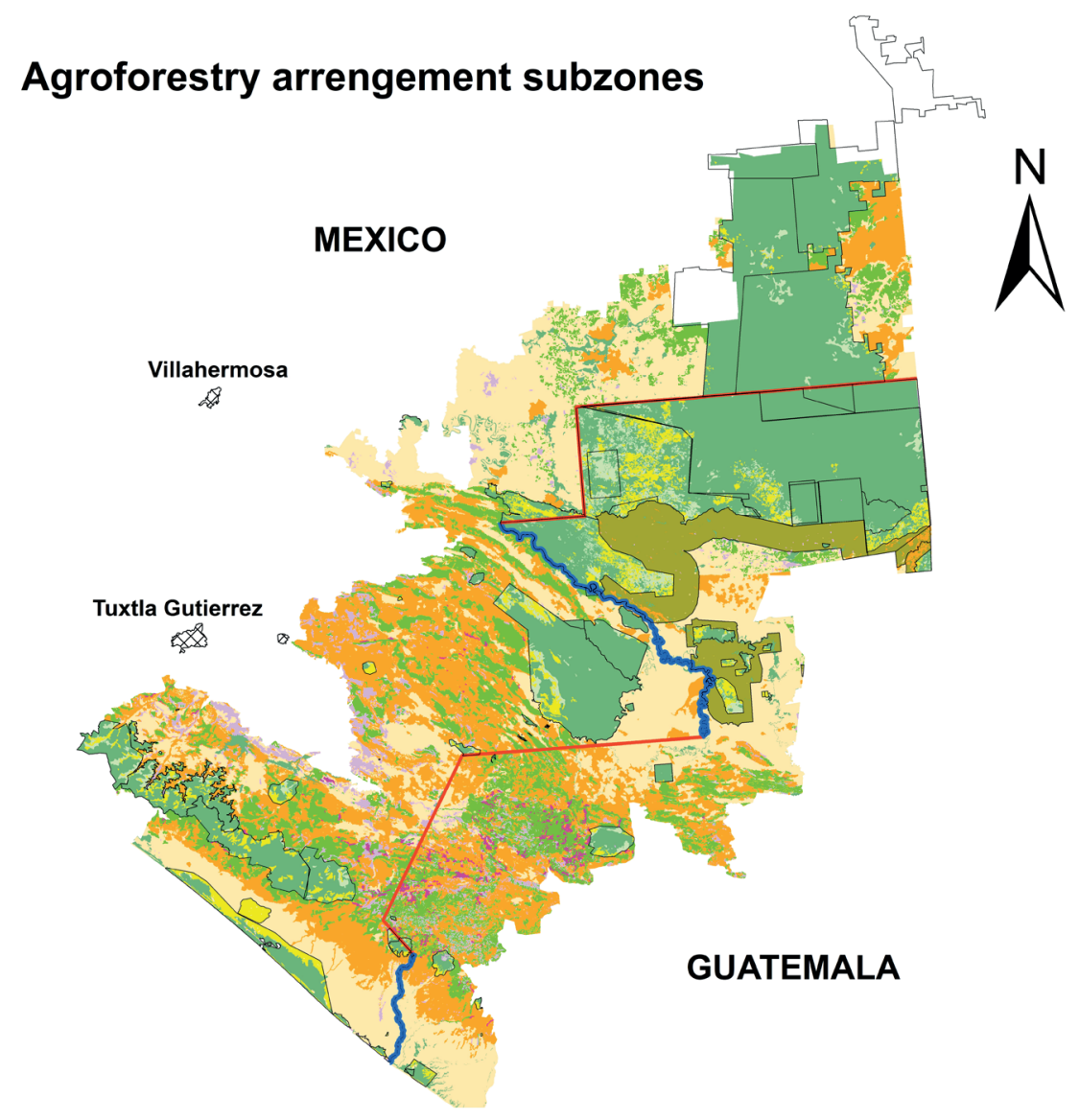

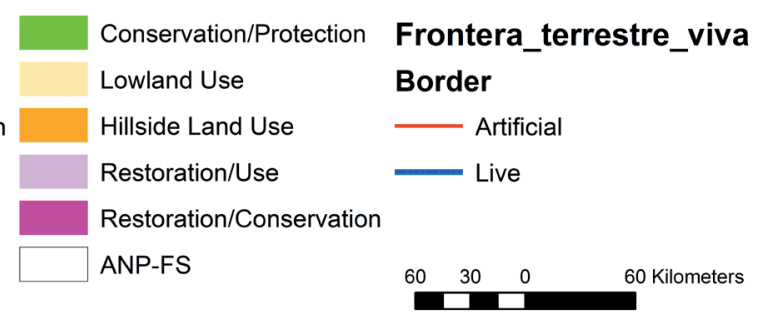

Fig. 4. Agroforest Zoning the Mexico - Guatemala trans-border region 


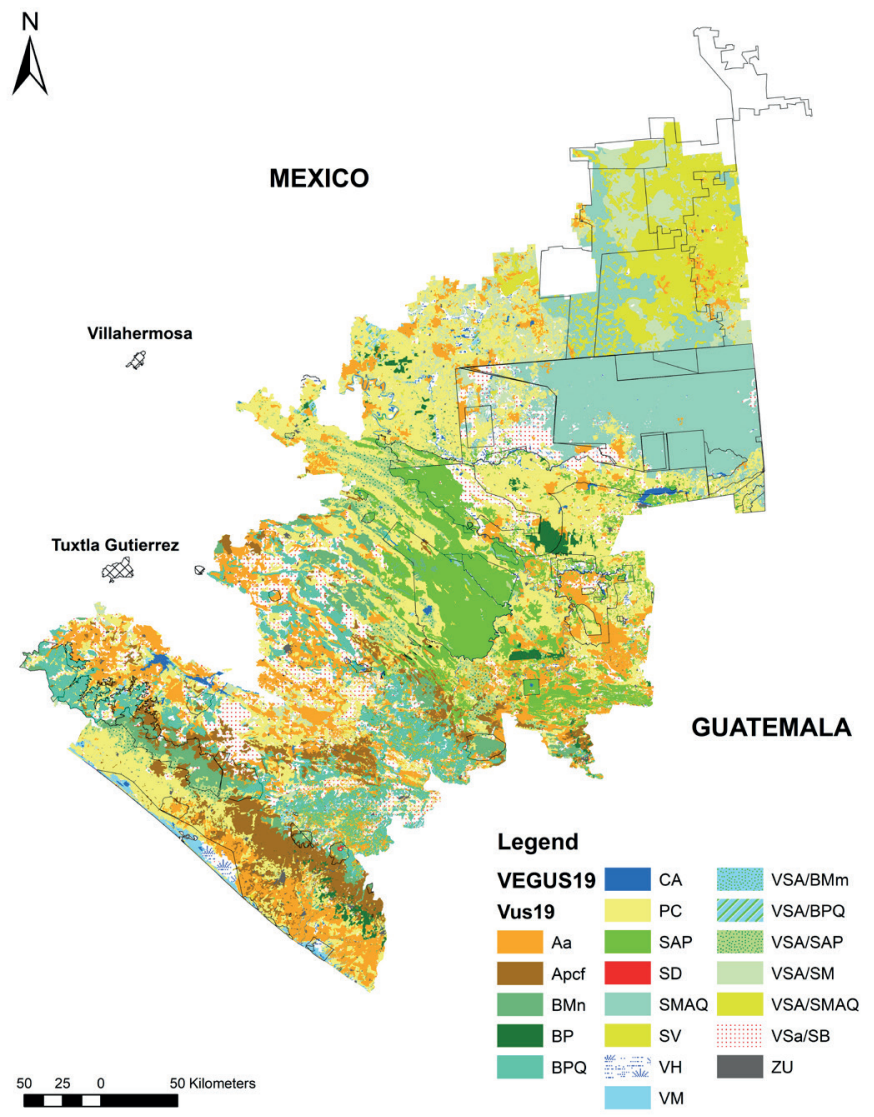

Fig. 5. Land cover and land use in the Mexico - Guatemala trans-border region 2019

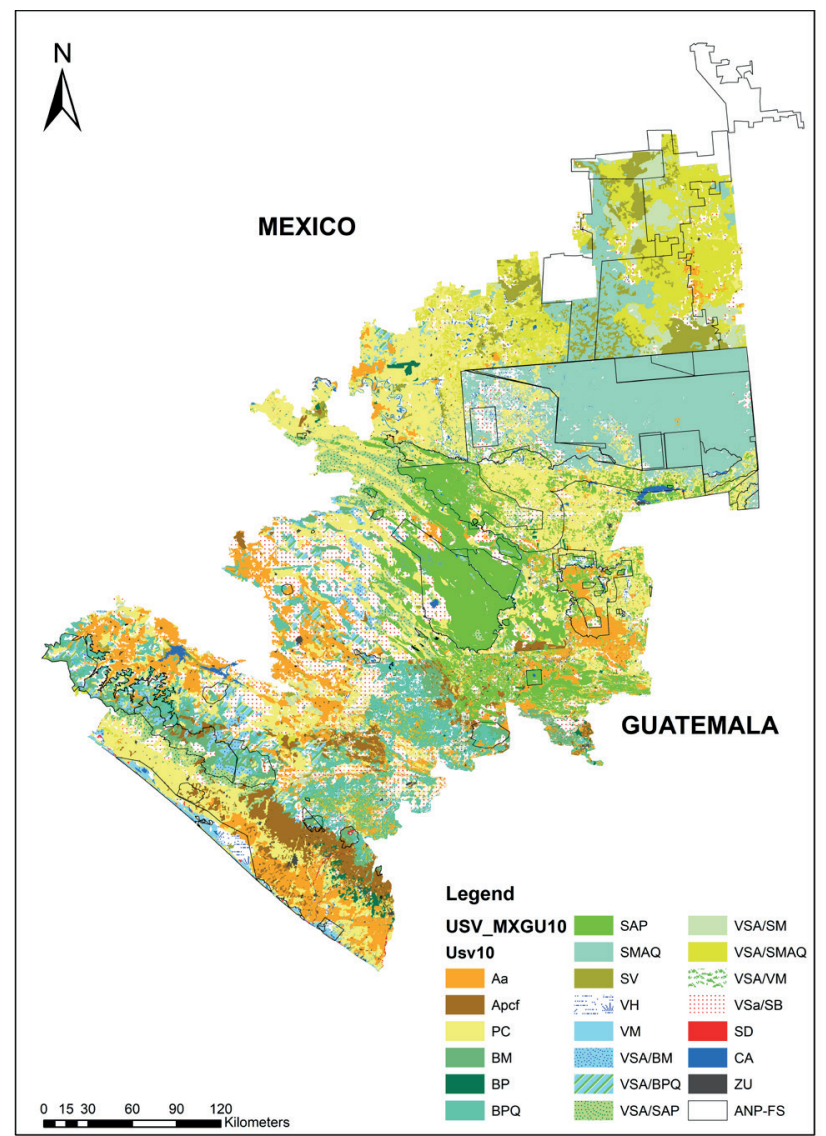

Fig. 6. Land cover and land use in the Mexico - Guatemala trans-border region 2010

Table 1. Land cover and land use inside and outside the Natural Protected areas- NPA (2010-2019)

\begin{tabular}{|c|c|c|c|c|c|c|c|}
\hline \multicolumn{2}{|l|}{ Land cover/Land use } & \multicolumn{3}{|c|}{ Area $\left(\mathrm{km}^{2}\right) 2010$} & \multicolumn{3}{|c|}{ Area $\left(\mathrm{km}^{2}\right) 2019$} \\
\hline Description & Symbol & Inside NPA & Outside NPA & Total & Inside NPA & Outside NPA & Total \\
\hline Agriculture & $\mathrm{Aa}$ & 1182.15 & 11519.1 & 12701.23 & 1951.12 & 14433.56 & 16384.68 \\
\hline Coffee, mango & Apcf & 245.87 & 3631.86 & 3877.73 & 798.89 & 5112.46 & 5911.35 \\
\hline Pastures & PC & 5760.04 & 19628.55 & 25388.59 & 6919.85 & 21762.90 & 28682.75 \\
\hline Plantation & $\mathrm{BP}$ & 25.70 & 560.98 & 586.69 & 301.62 & 896.86 & 1198.48 \\
\hline Forest shrub & VSA/SB & 6459.34 & 8431.63 & 14890.97 & 3146.51 & 7530.98 & 10677.49 \\
\hline Wetland & $\mathrm{VH}$ & 1039.67 & 659.40 & 1699.08 & 981.67 & 623.29 & 1604.96 \\
\hline Perennial Tropical forest & SAP & 6011.03 & 5592.76 & 11603.79 & 4961.21 & 4154.14 & 9115.35 \\
\hline Others forest & SV & 2802.59 & 471.54 & 3274.14 & 2005.09 & 737 & 2742.10 \\
\hline mangrove swamp & VM & 386.98 & 91.26 & 478.24 & 386.98 & 87.59 & 474.57 \\
\hline Temperate forest & $\mathrm{BPQ}$ & 944.69 & 4480.33 & 5425.02 & 1188.38 & 4972.31 & 6160.69 \\
\hline Mountain mesophyll forest & BMn & 1308.43 & 1547.33 & 2855.77 & 1385.28 & 2053.22 & 3438.50 \\
\hline High to medium perennial tropical forest & SMAQ & 14054.74 & 471.54 & 14526.28 & 13325 & 478.75 & 13803.74 \\
\hline Arboreal Mountain mesophyll forest & VSA/BM & 512.24 & 584.50 & 1096.74 & 10.27 & 66.16 & 76.43 \\
\hline Arboreal Temperate forest - Pinus Quercus & VSA/BP & 329.94 & 1566.27 & 1896.16 & 43.51 & 199.17 & 242.68 \\
\hline Arboreal Perennial Tropical forest & VSA/SAP & 557.07 & 2608.25 & 3165.32 & 532.51 & 2509.66 & 3042.17 \\
\hline Arboreal Others forest & VSA/SM & 1601.56 & 830.30 & 2431.86 & 5464.72 & 4790.85 & 10255.57 \\
\hline High to medium tropical forest & VSA/ SMAQ & 3624.34 & 4676.0 & 8300.34 & 22.03 & 0 & 22.03 \\
\hline Arboreal mangrove swamp & VSANM & 0 & 24.51 & 24.51 & 0 & & 0 \\
\hline Water & CA & 356.16 & 681.03 & 1037.19 & 281.33 & 595.26 & 876.59 \\
\hline Bare soil & SD & 23.34 & 67.30 & 90.64 & 9.73 & 4.43 & 14.16 \\
\hline \multirow[t]{2}{*}{ Urban area } & ZU & 60.27 & 576.38 & 636.65 & 76.02 & 764.39 & 840.41 \\
\hline & & & & $116,008.6$ & & & $116,008.6$ \\
\hline
\end{tabular}



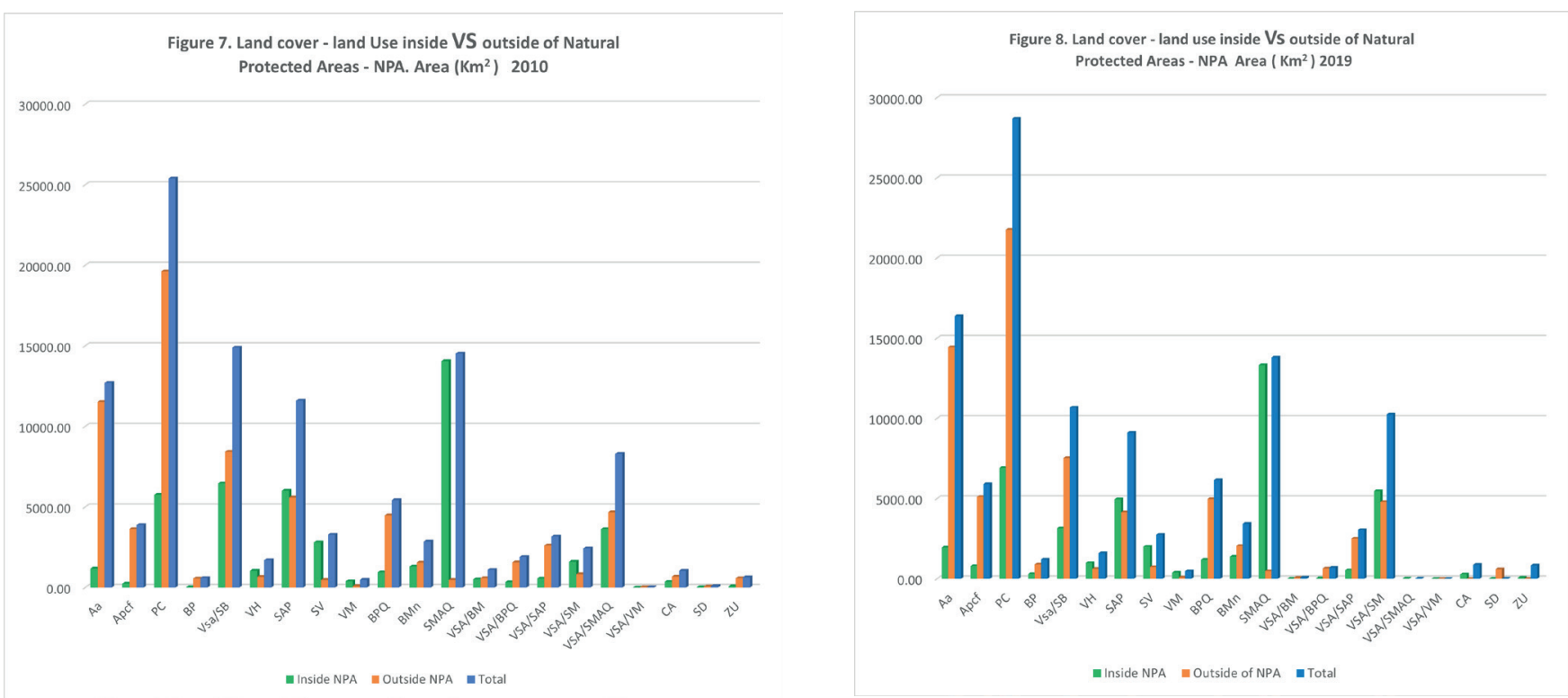

Fig. 7-8. Land cover and land use in the Mexico-Guatemala trans-border region (2010 - 2019)

The total area of forest cover, as well as the proportion of different ecosystems within the natural protected areas for the years 2010 and 2019 is shown in Figure 9. It can be seen that the most important ecosystem according to its area is tropical forest, among which the medium-high evergreen forest (SMAQ) and high evergreen forest (SAP) stands out. The former remains more or less constant over the study period and is mostly found within NPAs. The evergreen high forest (SAP) underwent the most significant changes due to the advancement of the Agricultural frontier. Other types of tropical forests are SV and VSA / SM, which include sub-deciduous, dry and thorny forests. The second most important ecosystem is temperate forest (BPQ), in general, it remains constant and only a small portion of it is found within NPAs. The third forest ecosystem consists of the mountain mesophyll forest. Finally, there is a small area entirely located within NPAs covered by mangrove forests, which is an ecosystem of high relevance from the perspective of its ecosystem functionality.

The area covered by shrub vegetation, which includes the lands where anthropogenic activity has put strong pressure on the ecosystems described above is also shown in Figure 9. In some cases, selective extraction of the arboreal vegetation was made, in other cases, the forest was completely removed to establish agriculture, generally by slash-and-burn cultivation shifting method. The shrub vegetation in these cases corresponds to secondary vegetation of different age (7-18 years). These areas may be subject to restoration of the original vegetation cover, the priority depends on several factors, such as slope (steep slope areas have higher priority), whether or not it corresponds to one protected area, and the quality of soil (which determines the suitability).

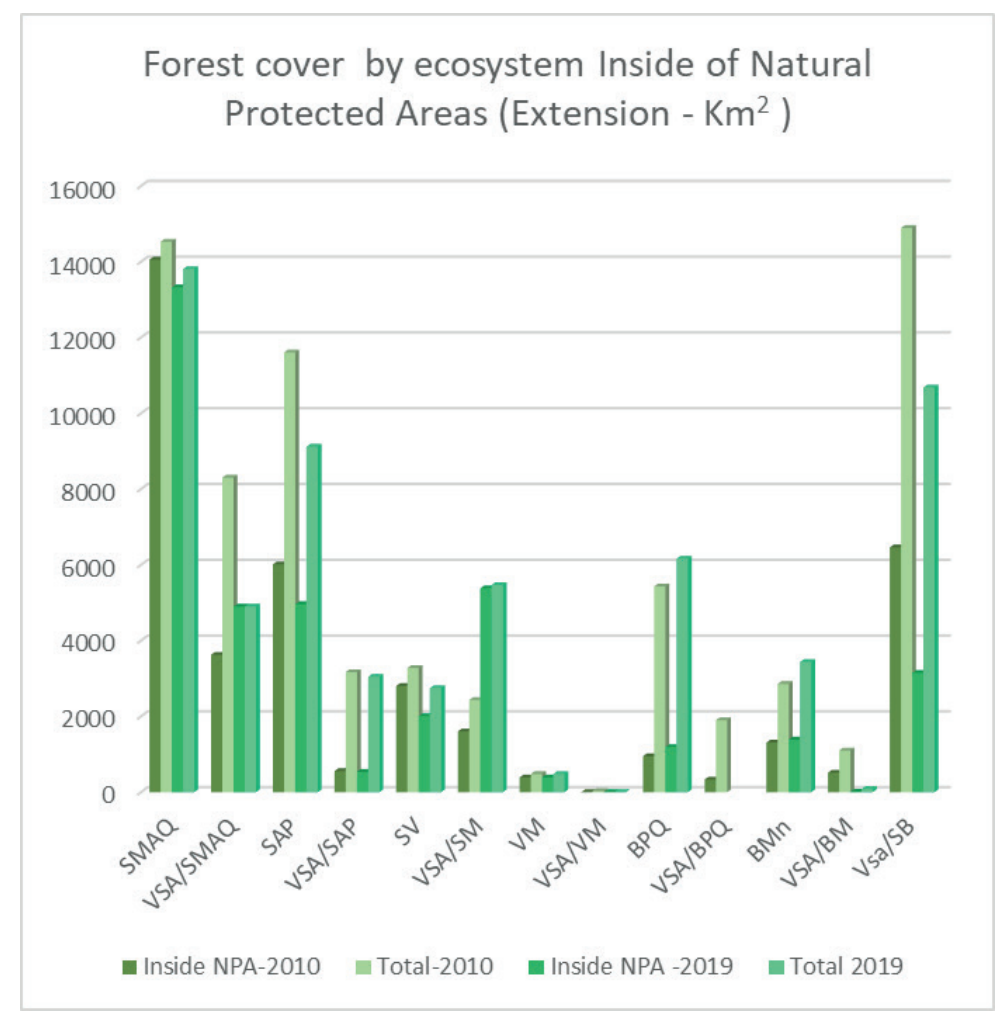

Fig. 9. Forest cover by ecosystem in the Mexico-Guatemala trans-border region 2010-2019²

${ }^{2}$ For desription of symbols see Table 1 
Nowadays, the NPAs, particularly in the MexicoGuatemala cross-border region, are a viable legal instrument as well as a planning tool that must be regularly strengthened to conserve their biological and cultural wealth. This has to be done by ensuring the continuity of the ecological and natural evolutionary processes, the natural supply of environmental goods and services as well as the permanence of natural resources that are necessary to maintain biological diversity, human and population well-being. From the data analyzed (Figure 9) it is evident, that NPAs play a fundamental role in the achievement of the Sustainable Development Goals, particularly Goal 15: Protect, restore, and promote sustainable use of terrestrial ecosystems, sustainably manage forests, combat desertification, halt and reverse land degradation and halt biodiversity loss.

The social valuation of nature at all levels is a fundamental element since it allows to ensure the essence and existence of NPAs. Greater financial support is also required to strengthen the environmental services through both national and binational programs and policies that promote and encourage the natural protected areas so that they can continue to contribute greatly to the Sustainable Development Goals.

\section{Conclusions and recommendations}

From the spatial analysis and modeling of agroforestry, that was performed to map the homogeneous units for environmental planning in the Mexico-Guatemala border region, the following conclusions and recommendations can be drawn:
- The Agroforestry zoning is an important tool to monitor forest areas in the context of achieving Sustainable Development Goals. In this study, it was used to define conservation and restoration areas.

- The total forest area in the region decreased from $47 \%$ in 2010 to $43 \%$ in 2019. About 60\% of the forest area is located inside the Natural Protected Areas and its principal ecosystem (according to its area) corresponds to the tropical forest (medium-high evergreen forest and high evergreen forest).

- It is evident that the natural protected areas play a fundamental role in the preservation of the forest in the region. The Natural protected areas (NPAs) are a viable legal instrument and a planning tool that must be strengthened regularly for the conservation of their natural resources, biological and cultural wealth as well as sustainable development.

- Zoning and management of forest areas and NPAs based on land suitability as well as agroforestry use are key tools to protect, restore and promote the adequate and sustainable use of terrestrial ecosystems and maintain their biological diversity.

- Hilly terrain with forestry aptitude and severe susceptibility to water erosion, which is currently devoted to annual agriculture, must be restored to its natural vegetation in order to reverse land degradation

- Natural vegetation or agroforestry must be promoted in high lands for environmental services to avoid the advancement of agricultural area.

\section{REFERENCES} 2019].

ASTER Global Digital Elevation Map - GDEM V3 (2019). [online] Available at: https://asterweb.jpl.nasa.gov/gdem.asp [Accessed 10 June.

National Commission of Natural Protected Areas, CONANP (2014). Federal Natural Protected Areas of the Mexican Republic at different scales. México.

CONAFOR (2011). National Forestry Commission, Agreement by which the Forestry Zoning is integrated and organized. Official Journal, November 2011.

Conservation International -Program México y America Central (2004). North region of HOTSPOT of Mesoamerica's biodiversity, Belize, Guatemala, México. Critical Ecosystem Partnership Fund, 64

Domínguez et al. (2008). Environmental zoning for land management of the municipal watershed of the Aguas Calientes River, Nicaragua. Natural Resources and Environment, 55.

FAO (1998). World Reference Base for Soil Resources, by ISSS-ISRIC-FAO. World Soil Resources Report No. 84. Rome.

Global indicator framework for the Sustainable Development Goals and targets of the 2030 Agenda for Sustainable Development.

[online] Available at: https://unstats.un.org/sdgs/indicators/Global Indicator Framework after review_Eng.pdf. [Accessed 11 July. 2019].

Guillén T. (2017). Cross-border labor market Mexico - Guatemala, demographic footprint in Chiapas? Centro GEO/CIDE (Unpublished).

INEGI (2007). Soil vector data set scale 1: 250000 Series II (National Continuum) México, [online] available at: http://www.inegi.org.mx/

geo/contenidos/recnat/edafologia/default.aspx. [Accessed 15 July. 2018].

INEGI (2016). Soil use and vegetation vector data set, scale 1:250 000, Series VI México.

López D. y Saavedra A. (2007). Proposal for a Management and Conservation Plan for the Canyon Rio Becerra, Tlapizahuaya - Becerra -

Jalalpa). Project Management Program for the Canyon Rio Becerra. Technical Report (Unpublished). CENTROGEO, México, D. F

López D. y Saavedra A. (2019). The natural environment and the suitability of the land, bases for the Transboundary Rural Management

Mexico - Guatemala. CentroGeo, Mexico City López D.,

Saavedra A. y Castellanos L. (2016). Diagnosis, Forecast: The current situation, strategies and guidelines for forest management. Chapter

Tabasco, Second Report (Unpublished). CENTROGEO, México, D. F.

López Á, Lozano P. y Sierra-Correa C. (2012). Environmental Zoning Criteria Using Participatory and Information Techniques. Case Study

Atlantic Department Coastal Zone. Bol. Invest. Mar. Cost. 41 (1). Santa Marta, Colombia.

Ortiz-Lozano A., Granados-Barba y Espejel I. (2009). Ecosystemic zonification as a management tool for marine protected areas in the coastal zone: applications for the sistema arrecifal Veracruzano National Park, Mexico. Ocean Coast. Manag. 52: 317-323

Saavedra A. y Castellanos L. (2013). The Physiographic Classification of the Usumacinta River Basin Region. CENTROGEO - FORDECYT.

Technical Report (Unpublished). México, Centro de Investigación en Geografía y Geomática "Ing. Jorge L. Tamayo" A.C.

Saavedra A., López D. y Castellanos L. (2016). Analysis of the factors of territorial transformation in the biological corridors of Northern Chiapas. Technical Report Mexico, Centro de Investigación en Geografía y Geomática "Ing. Jorge L. Tamayo" A.C.

Valenzuela E. y Silva A. (2003). Environmental zoning. In: Environmental Management Plan of the Tibanica Wetland District Ecological Park, Bogotá. [online] available at: http://www.ambientebogota.gov.co/web/sda/planes-de-manejo-ambiental 1. [Accessed 21 June. 2018]. 